manifestations. We did not observe any serious adverse events. Such low levels of platelet count for platelet transfusion have been used by earlier workers as well ${ }^{2}$

$$
\begin{array}{r}
\text { Jagdish Chandra and Rahul Naithani } \\
\text { Deptt of Pediatrics } \\
\text { Lady Hardinge Medical College, } \\
\text { Kalawati scran children's Hospital, New Delhi. } \\
\text { E-mail: jchandra55@yahoo.co.in } \\
\text { [Dol-10.1007/s12098-009-0104-3] }
\end{array}
$$

\section{REFERENCES}

1. Chandra J, Naithani R, Ravi R et al. Antithymocyte Globulin and Cyclosporin in Children with acquired Aplastic anemia. Indian J Pediatr 2008;75:229-233.

2. Sagmeister M, Oec L, Gmur J. A resprictive platelet tranfusion policy allowing long term support of put patients with severe aplastic anemia. Blood 1999; 93:31243126.

Picture of the Month

\title{
Carpenter's Syndrome: A Rare Craniofacial Dysmorphic Syndrome
}

Sir,

We report a case of carpenter's syndrome in a child of consanguineous marriage. The child was having cleft lip and turricephaly, polydactyly in both hands, polydactyly and syndactyly in lower limbs. (Fig. 1). The patient was evaluated with MRI. T1W axial view MRI was showing cortical atrophy, corpus callosum agenesis, and in sagital view tower shaped skull, and ventricles seem to be single due to cortical atrophy (Fig. 2). There was no cardiac anomaly on echocardiography.

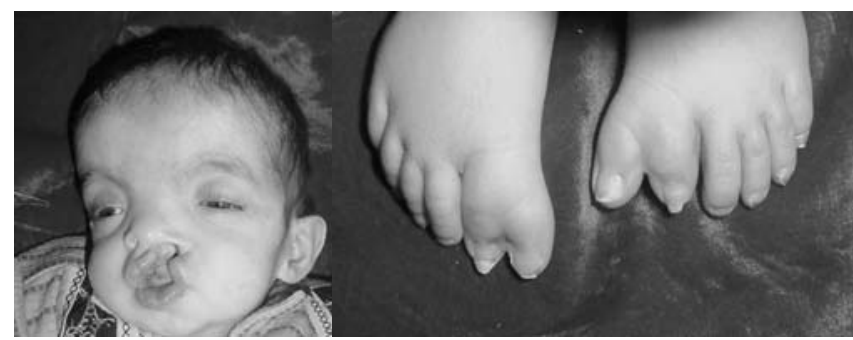

Fig. 1. Clef lip with hypertelorism and polydactyly and syndactyly in left.

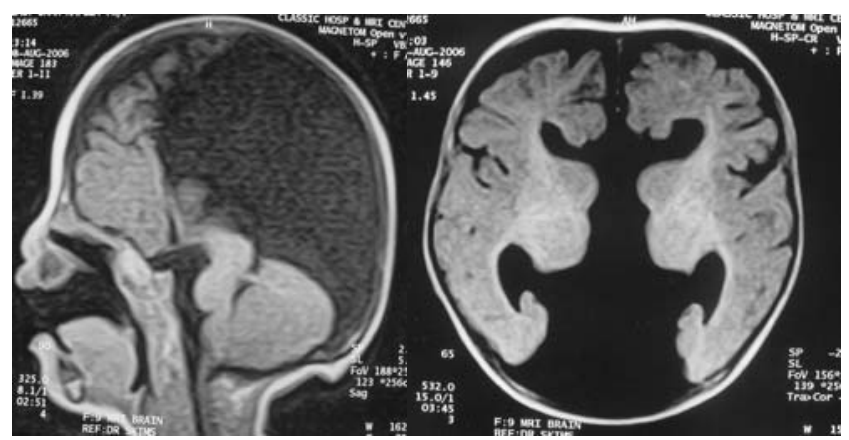

Fig. 2. MRI showing tower slaped skell and cortical atrophy in sagital view. And cortical atrophy corpus callosum agenesis in axial view. Ventricals seem to be single.
Carpenter's syndrome also known as acrocephalosyndactyly II, is a very rare craniofacial dysmorphic syndrome with less than 50 cases being reported in literature. Carpenter in 1909 described two sisters and a brother with acrocephaly, peculiar facies, brachydactyly and syndactyly in hands and preaxial poldactyly and syndactyly in toes. ${ }^{1}$ These patients have coronal synostosis leading to tower shaped skull. Intelligence is usually low in most of the cases, though a few cases with normal intelligence have been reported. ${ }^{2,3}$ The cardiac anomalies may or may not be associated. ${ }^{4}$ The associated pre maxillary agenesis can lead to cleft lip and palate. Etiology of this rare syndrome is not clearly known but has a well-established autosomal recessive inheritance as is evident by parents of the patient being cousins in some cases. ${ }^{5}$

Abrar A. Wani, Tanveer I. Dar, AU Ramzan, Altaf Ali Department of Neurosurgery, Sher-i-Kashmir Institute of Medical Sciences, Srinagar, Jammu and Kashmir, India E-mail:abrarwani@rediffmail.com

\section{REFERENCES}

1. Carpenter G. Case of acrocephaly with other congenital malformations. Proc Roy Soc Med 1909;2: 45-53, 199-201.

2. Taravath S. Tonsgard JH, Cerebral malformations in Carpenter syndrome. Pediatr Neurol 1993; 9 : 230-234.

3. White J. DB Boldt, DJ David, L Sheffield, DA Simpson. Carpenter syndrome with normal intelligence and precocious growth. Acta Neurochirurgica 1981; 57: 43-49.

4. Owen RH. Acrocephalosyndactyly: a case with congenital cardiac abnormalities. Brit J Radiol 1952; 25 : 103-106.

5. HM Farag, SM Kotb, GA Sweify, RK Fawzy, SR Ismail. A diagnostic clinical genetic study of craniofacial dysmorphism. Eastern Mediterranean Health Journal 1999; 5: 470-477. 